\title{
Conjugando consensos acerca da formação identitária do mediador de conflitos
}

\author{
Conjugating consensuses on the identity formation of conflicts mediator \\ http://dx.doi.org/10.5007/2178-4582.2015v49n1p69
}

\section{Aurila Eurídice Carneiro da Cunha Souza}

Centro de Mediação Tribunal de Justiça do Rio de Janeiro, Rio de Janeiro/RJ, Brasil

\begin{abstract}
Este artigo é resultado de um trabalho monográfico de pós-graduação, que teve como finalidade refletir acerca da formação identitária do mediador de conflitos. A metodologia utilizada parte de uma investigação bibliográfica, com destaque para a trajetória e estruturação da Mediação no cenário nacional, objetivando examinar os processos de elaboração do conhecimento e de intervenção prática do mediador de conflitos na sociedade brasileira. Faz uso de um enfoque dialético que reconstitui o contexto social em que o profissional está inserido, as peculiaridades que marcam esse lugar na contemporaneidade, bem como os meios consensuados em que estão envolvidas as dinâmicas desse processo. O estudo fundamenta a construção do processo identitário na dialética da diferença e da igualdade, compreendendo o ofício do mediador como uma constante construção, utilizando conceitos da Psicologia Social e do Multiculturalismo. Por fim, conclui como transitar por fronteiras na mediação mostra que o saber produzido circula e coloca em jogo a construção da subjetividade.
\end{abstract}

Palavras-chave: Mediação de Conflitos - Identidade - Multiculturalismo - Psicologia Social
This article is the result of a postgraduate monograph, which is intended to reflect upon the construction of the identity of the conflict mediator. Its methodology is based on a bibliographical research, with emphasis being placed on the trajectory and the structural organization of Mediation nationwide, aiming to examine a mediator's processes of knowledge elaboration and practical intervention inside the Brazilian society. It takes a dialectic approach in order to rebuild the social context in which such a professional works as well as the peculiarities that characterize that place in the contemporary world and the agree$d$-upon means involved in the dynamics of such processes. Centered on the process of identity formation in the dialectics of difference and equality, this study understands the mediator's role as work constantly in progress, making use of concepts from Social Psychology and Multiculturalism. Finally, it also concludes how transiting through borders in mediation shows that the produced knowledge circulates and brings into play the construction of subjectivity.

Keywords: Conflict Mediation - Identity - Multiculturalism - Social Psychology

\section{Introdução}

Este artigo tem por objetivo problematizar como o surgimento desse recente ator que atua para promover o diálogo e o respeito às diferenças pode conjugar consensos acerca de sua formação identitária. Busca a reflexão sobre o ofício do mediador, dentro do contexto de uma sociedade que se quer para a diversidade cultural, em que os métodos consensuais de solução de conflitos ocupam um crescente espaço na mídia e nos debates públicos e jurídicos. Situar historicamente um novo paradigma para trabalhar com as controvérsias e o incremento da Mediação como um recente instrumento de tratamento 
dos conflitos não é tarefa simples. Entretanto, sua relevância dá-se quando os elementos que se interligam e contribuem para refletir sobre a importância da construção do consenso na vida contemporânea e, consequentemente, $o$ contexto social em que o mediador está inserido, localizam conceitos e ideias que constroem uma multiplicidade de alternativas.

Entender a importância e a necessidade de concentrar esforços para desvelar o processo de constituição identitária do mediador como um profissional comprometido com uma prática emancipadora e democrática pode auxiliar a identificar os processos de elaboração do conhecimento e de intervenção prática que são necessários a esse ofício. Prioriza também elucidar como a crítica teórica - no plano da pesquisa e da reflexão - pode contribuir para despertar o interesse da comunidade acadêmica para a temática, bem como propagar de que modo a mediação de conflitos articula-se em torno da autonomia e da cidadania, no sentido das pessoas se autodeterminarem em relação com os outros e, também, na produção das diferenças.

Para tanto, inicialmente, o estudo apresenta os pressupostos que sustentam a cultura da mediação como instrumento no tratamento dos conflitos. Realiza uma análise sistemática do contexto da promoção e do aprimoramento da prática do mediador, ordenando e definindo a relação estabelecida entre esse conjunto de saberes. Fundamenta a construção do processo identitário na dialética da diferença e da igualdade, compreendendo o ofício do mediador como uma constante construção utilizando referências da Psicologia Social e do Multiculturalismo. Por fim, conclui que o ofício da mediação transita por fronteiras e que o saber produzido circula e coloca em jogo a construção da subjetividade. Espera-se que o artigo impulsione o debate sobre as discussões que envolvem o tema da identidade do mediador, abra diálogos no campo do pluralismo e produza elementos que contribuam para refletir sobre o enfrentamento da inclusão perversa que ameaça a justiça social no contexto da globalização.

\section{A Mediação em perspectiva de ação}

O reconhecimento das deficiências infraestruturais do Estado, os efeitos das políticas de ajuste no capitalismo brasileiro, a liberalização da economia e os desafios lançados à governança estatal vêm colocando em xeque como responder a um maior dinamismo econômico, bem como a seus efeitos.

Hoje, as novas relações sociais apresentam transformações relevantes e suscitam cada vez mais dúvidas quanto ao resgate do espaço da prática política na sociedade contemporânea. Isto ocorre, principalmente, quando se trata da responsabilização de setores como a função jurisdicional que apresenta 
limites e acentua antigos mecanismos de discriminação e exclusão de grande parte da população.

Em decorrência desse desregramento das organizações públicas e da inscrição da violência no Estado e nas estruturas sociais observam-se sequelas perversas, sobretudo na sociabilidade urbana e nas instituições democráticas. A violência, transformada em problema político (SOARES, 2006), reflete não somente uma crise do Estado, mas afeta, sobremaneira, a liberdade e os direitos fundamentais. Nestes termos, a luta pela igualdade de direitos tem sido cotidianamente violada e o espaço judiciário, reservado tradicionalmente para a solução dos conflitos, ainda se apresenta incipiente e ineficaz.

Santos Jr. (2003), ao discutir a questão do acesso à Justiça salienta que as estatísticas demonstram que grande parte dos conflitos que tramitam no Judiciário é resolvida sem resolução de seu mérito, ou seja, com soluções processuais quase sempre impositivas e que pouco equacionam as demandas. Resolvem-se as lides ora por processos pacíficos, ora por soluções violentas de todo tipo, o que, de acordo com o autor, deixa de ser um problema apenas da Justiça, mas de toda a cidadania, exigindo a aplicação de políticas de reaproximação do Estado, entre elas, "o reforço às atividades de educação para transformar uma cultura violadora de direitos em cumpridora desses direitos" (SANTOS JR., 2003, p. 8).

Esse esforço pressupõe um tipo ampliado de participação, pois implica na capacidade de diferentes grupos influenciarem, direta ou indiretamente, as políticas públicas. Segundo Demo (2002, p. 172), o direito radical de participação política tem como meta combater e superar a pobreza política, o que só será possível com competência política, assim entendida como "competência propriamente humana de constituir-se sujeito consciente e capaz de orientar seu destino, dentro das circunstâncias dadas".

Para o enfrentamento desta questão complexa, a Educação para os Direitos Humanos, voltada para o fortalecimento do Estado Democrático de Direito e da Cultura de Paz (BRASIL, 2012) tem sido defendida por inúmeros autores (JACOBI, 2000; BENEVIDES, 2003; TORO, 2004; DEMO, 2002; SOUZA SANTOS, 1993; 2005), tornando-se prioridade e eixo fundamental das políticas públicas.

O conceito de Cultura de Paz adquiriu dimensão pública por ocasião do ano 2000, quando foi proclamado pela Assembleia Geral das Nações Unidas o Ano Internacional por uma Cultura de Paz. A UNESCO foi responsável pela coordenação das atividades de comemoração do Ano Internacional por uma Cultura de Paz e pela distribuição do "Manifesto 2000 Para uma Cultura 
de Paz e de Não-Violência", documento redigido por um grupo de Prêmios Nobel da Paz, com mais de cem milhões de assinaturas.

Segundo Guimarães (2006), a paz tem emergido no diálogo da comunidade internacional como uma alternativa à violência, de forma que podemos localizar na sociedade as mudanças que estão em curso hoje por uma construção da cultura da paz, entre elas, as manifestações de ampliação das práticas pacíficas, o recrudescimento da cultura dos direitos humanos, o fomento da prevenção e resolução de conflitos e o avanço de estratégias de segurança humana.

Uma das proposituras defendidas por Luis Alberto Warat (2003) - renomado professor de Direito -, elaborada para o Ministério da Educação em favor da Educação para os Direitos Humanos, sugere o abandono da compreensão de Direitos Humanos, estabelecida sob o paradigma da modernidade para uma nova política educativa de Direitos Humanos, compreendida como uma nova mobilidade do Direito a ter direitos sob outra concepção jurídica - a da democracia e da cidadania. Warat (2003) decodifica o direito em direção a uma educação libertária, deixando de ser uma problemática somente jurídica para adquirir condição de prática política, que reivindica e evidencia a ausência de uma dimensão pedagógica dentro das práticas de administração da justiça.

Essa perspectiva impulsionou, segundo ele próprio, a conquista de espaços pela 'mediação preventiva nas práticas jurídicas', o que estimulou um exame crítico da função dos operadores do Direito em favor de uma nova leitura não excludente, viabilizando o ofício em práticas de ajuda e resolução não violenta dos conflitos, ou seja, em uma educação para a paz que compreenda os conflitos de forma positiva, sem a violência estatal e os seus instrumentos policiais e judiciais.

No campo da prevenção e resolução de conflitos, a mediação não se evidencia como um exercício de ação do senso comum. Segundo Muszkat (2005, p. 12), "a mediação implica um saber, uma episteme, resultante de vários outros saberes, cuja transversalidade fornecerá o instrumental para uma prática que pressupõe a planificação e aplicação de uma série de passos ordenados no tempo" (MUSZKAT, 2005, p. 13). E ainda, segundo a autora, o propósito de "buscar acordos entre pessoas em litígio por meio da transformação da dinâmica adversarial, comum no tratamento dos conflitos, para uma dinâmica cooperativa, improvável nesse contexto" (Ibid., p. 13) é realizada por um terceiro facilitador, imparcial, que terá o papel de desenvolver as partes para um resultado satisfatório e que possa ser multiplicado para outras situações de conflito no decorrer da vida. 
Para tanto, segundo Muszkat (2005), é importante o mediador reconhecer a complexidade do seu fazer e abrir-se ao conhecimento das diferentes áreas como Psicologia, Direito, Filosofia, Sociologia e Teorias da Comunicação. De acordo com a autora, a mediação não deve ser compreendida como um modo isolado do conhecimento, mas como "uma transdisciplina voltada para o estudo da pacificação dos conflitos nas inter-relações íntimas e sociais" (MUSZKAT, 2005, p. 15), o que a demarca como uma importante forma de horizontalizar as relações humanas (RIBEIRO; STROZEMBERG, 2001; SALES, 2004; GERGEN, 1999; WARAT, 2003; FOLGER E BUSH, 1999; MOORE, 1998; CEZAR-FERREIRA, 2007), em que o mediador aparece como um veículo importante para a promoção da alteridade (OLTRAMARI, 2009).

Avançando na construção de um novo modelo de tratamento dos conflitos, Splenger e Splenger Neto (2010) defendem a Mediação como uma política pública de inclusão social. Sustentam que o Judiciário tem como objeto a decisão dos conflitos, mas não a eliminação dos mesmos. E problematizam:

\begin{abstract}
Consequentemente, o Judiciário funcionaliza (no sentido de que institucionaliza) ou processa conflitos sociais, mas suas decisões não eliminam relações sociais. Na verdade, ele decide sobre aquela relação social especificamente demandada, o que não impede, todavia, que outras tantas, com novas características, se manifestem ou que continue existindo a própria relação social enquanto relação social" (SPLENGER; SPLENGLER NETO, 2010, p. 24).
\end{abstract}

Dessa maneira, a Mediação de Conflitos apresenta-se como um processo que busca um entendimento comum sobre os direitos dos interessados, interferindo de modo efetivo na valorização daqueles que estão radicados em suas experiências. Oltramari (2009, p. 256) alerta que é neste momento que surge a "possibilidade de que os sujeitos mediados entendam que são partes responsáveis pelo conflito em que se envolveram".

Seguindo essa linha de raciocínio, observa-se, adiante, uma tendência dos estudiosos reportarem-se a esse debate com fins de dinamizar o tema da alteridade. Para Splenger (2010, p. 322), a Mediação como um novo modelo de composição dos conflitos "desmancha a lide", pois quando o mediador transforma a dinâmica adversarial em consensuada, ele contribui para que as partes tomem a responsabilidade em suas mãos e concluam por uma melhor solução. E conclui: "Paralelamente à ética da alteridade, deve-se pensar a outridade no sentido de 'captar o outro': é necessário captar a ética do outro e a honestidade que trata de instalar em sua outridade" (SPLENGER, 2010, p. 322).

Conforme definido por Houaiss (2002), a palavra mediação procede do latim mediare e refere-se ao "ato de servir de intermediário entre pessoas, gru- 
pos, partidos, facções, países etc., a fim de dirimir divergências ou disputas". Portanto, a partir da noção de que mediar significa intervir, estar entre (duas coisas), estar no meio de, é fundamental tornar inequivocamente explícito que a comunicação é um recurso e instrumento de grande valia neste estudo.

Warat (2004, p. 67) salienta que a comunicação é uma ferramenta ímpar, pois na experiência da mediação "é fundamental trabalhar os não-ditos do sentido", uma vez que, em geral, estes encontram-se subjacentes àqueles expressos. De fato, atentar para o exercício e para a prática social e política da linguagem na mediação são tarefas que demandam esforços. Significa estar atento à necessidade de compartilhar o direito de ser ouvido e reconhecido como um membro argumentativo por práticas do bem comum, como propõe a democracia habermasiana, em que todos estejam implicados como sujeitos iguais no diálogo.

Assim explora Habermas, em sua "Teoria do Agir Comunicativo", quando defende que a capacidade argumentativa ocorre quando é possível participar de construções sociais sem que um renuncie o direito do outro, de forma a construir um "nós". Propõe, assim, uma estrutura dialógica aberta em interação de no mínimo duas pessoas, falando e agindo com objetivo de alcançar o entendimento.

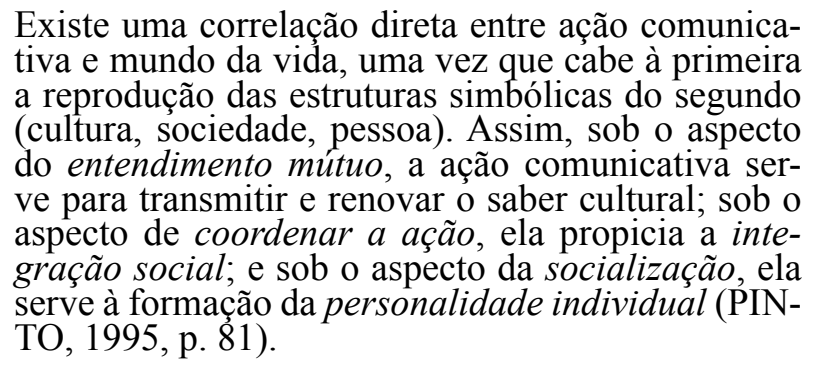

Dentro dessa mesma ótica, outra contribuição notadamente eficaz e presente nos estudos dos métodos consensuais de solução de conflitos é a Comunicação Não-Violenta (CNV). É uma abordagem de comunicação reconhecida internacionalmente que vem revolucionando as relações interpessoais e a gestão institucional, propiciando um diálogo efetivo e sustentável entre os povos e os indivíduos em conflito, que tem como objetivo criar alternativas pacíficas de diálogo, como ensina o seu idealizador Marshall B. Rozemberg:

Ela nos guia no processo de reformular a maneira pela qual nos expressamos e escutamos os outros, mediante a concentração em quatro áreas: o que observamos, o que sentimos, do que necessitamos, e o que pedimos para enriquecer nossa vida. A CNV 
promove maior profundidade no escutar, fomenta o respeito e a empatia e provoca o desejo mútuo de nos entregarmos de coração. Algumas pessoas usam a CNV para responder compassivamente a si mesmas; outras, para estabelecer maior profundidade em suas relações pessoais; e outras, ainda, para gerar relacionamentos eficazes no seu trabalho ou na política. No mundo inteiro, utiliza-se a CNV para mediar disputas e conflitos em todos os níveis (ROZEMBERG, 2006, p. 32).

A partir de tais considerações, podemos afirmar que a Mediação, como instrumento de consenso, nasce como estratégia para servir à prática democrática ao tratamento do conflito em que se exige mais do que boa-fé, mas, sim, compromissos para enfrentar e lidar com as relações de convivência e conflitos entre culturas plurais.

\section{A consolidação da Mediação no Brasil}

Christopher W. Moore é um mediador internacionalmente conhecido, consultor em vários países, planejador de sistemas de administração de controvérsias e importante autor neste campo. Em seu didático trabalho " $\mathrm{O}$ Processo de Mediação: estratégias práticas para a resolução de conflitos”, Moore (1998) examina minuciosamente a promoção e o aprimoramento da prática do mediador na sociedade americana. Tem como objetivo explorar o debate sobre como a instituição do consenso na vida contemporânea converge para o processo de formação identitária do sujeito mediador.

Demonstra que à medida que o trabalho do mediador vai amadurecendo, procedimentos mais formais e profissionalizados acompanham a sua ação de forma a alcançar uma prática excelente. Sistematiza alguns dos desenvolvimentos do campo que têm contribuído para um fazer de qualidade, descrevendo e examinando como algumas atividades ligadas ao exercício do mediador progridem ao longo da história na América do Norte, e também em outros países. Entre elas, a saber:

- O trabalho em rede e a troca de informações que circulam pelas organizações;

- Códigos de ética e padrões de prática que estabeleçam um bom desempenho;

- Seminários, Treinamento e Desenvolvimento Profissional do Mediador;

- Qualificação e Competência para a qualidade. 
Nesse viés, à luz dessas atividades, com objetivo de sistematizar o debate teórico e metodológico, os quatro processos de análise propostos por Moore (1998) foram investigados em nossa realidade de modo a oferecer um panorama sobre como está sendo conduzida a formação prática do mediador no Brasil.

Associações, organizações e redes

Informações encontradas em pesquisa bibliográfica e via internet indicam que a Mediação cresce exponencialmente no Brasil a partir de três momentos: a) com o Movimento pela Conciliação (2006), que nasceu sob a iniciativa do CNJ - Conselho Nacional de Justiça, a partir da mobilização interna de juízes, com objetivo de conclamar os operadores de Justiça, os usuários e a sociedade para promover a cultura da conciliação e os métodos consensuais; b) com o advento das formas autocompositivas e alternativas de solução de conflitos, que objetiva uma mudança cultural no tratamento dos conflitos visando à decisão consensual das partes envolvidas, através dos mecanismos da conciliação e da mediação; c) e após as repercussões que sucedem à Resolução $n^{\circ}$ 125/2010 do CNJ - Conselho Nacional de Justiça, que institui a Política Judiciária Nacional de tratamento de conflitos de interesses, assegurando a todos a solução dos conflitos por meios adequados à sua natureza e peculiaridade.

Dados revelam também que a partir dos anos 1980, devido à sobrecarga dos tribunais e à insatisfação da população quanto ao acesso à Justiça, diferentes experiências despontam no campo da resolução de conflitos. Entre elas, os Juizados Informais de Conciliação, os Juizados Especiais de Pequenas Causas e, principalmente, a importante iniciativa do governo em nomear uma comissão de juristas para constituir um anteprojeto de lei, iniciando assim, uma longa caminhada até 1996, que resulta com a Lei de Arbitragem, que faz menção à Mediação (CARMONA, 2011).

Contudo, somente a partir do $1^{\circ}$ Seminário de Mediação de Conflitos (1992, EUA), liderado por Melvin Rubin, um dos criadores da ADR - Alternative Dispute Resolution, é que as primeiras organizações voltadas para esse objetivo emergem no Brasil. Para responder ao avanço da litigiosidade e da violência na sociedade brasileira é criado, em 1994, o IMAB - Instituto de Mediação e Arbitragem do Brasil (SP). Surge como uma entidade sem fins lucrativos, com objetivo de estimular a pesquisa, a divulgação e o desenvolvimento técnico e científico dos métodos de soluções de conflitos em vários estados brasileiros, a fim de oferecer ao público uma alternativa para resolver suas controvérsias. 
Em 1995, desponta a ABRAME - Associação Brasileira de Mediadores (PR) que, após um ano de lançamento, inaugura um projeto de aplicação das técnicas da mediação na conciliação judicial nos recém-criados Juizados Especiais Cíveis de Curitiba, passando a desenvolver diferentes ações junto às Varas Especializadas de Família, Infância e Juventude, e na área comercial. A ABRAME, em 2003, mudou sua razão social para Associação Brasileira de Árbitros e Mediadores, visando ampliar suas possibilidades de atuação.

Em seguida, entre outras em diversos estados, duas importantes entidades são fundadas: em 1997, o CONIMA - Conselho Nacional das Instituições de Mediação e Arbitragem (SP); e o MEDIARE - Centro de Mediação e Arbitragem de Resolução Ética de Conflitos do Rio de Janeiro (RJ). O primeiro - fundado um ano após a Lei de Arbitragem - tem como principal objetivo reunir e representar as organizações e associações de mediação e arbitragem, visando à excelência de sua atuação. No caso do MEDIARE, este desponta como uma instituição privada, que apresenta um crescimento gradativo, tendo como objetivos a divulgação, a capacitação, a consultoria e a prática da Mediação.

Em 1998, surgem outras entidades relevantes após ser decretado o Projeto de Lei 4.827/98. O projeto, então elaborado pela Deputada Federal Zulaiê Cobra, tem mais tarde o seu texto alterado pelo Senador Pedro Simon que criou o projeto substitutivo (PLC 94/2002), que institui e disciplina a Mediação como método de prevenção e solução consensual de conflitos na esfera civil, ainda em tramitação. Surgem, então, novas entidades: o CBMA - Conselho Brasileiro de Mediação e Arbitragem (2002), visando promover os meios alternativos de solução de conflitos e, em especial, a mediação e a arbitragem, orientando e informando as vantagens dos processos; o CEMAPE - Centro de Mediação e Arbitragem de Pernambuco, que contribuiu na orientação ética apropriada para o processo de mediação (SALES, 2003); e o FONAME - Fórum Nacional de Mediação (2007), que tem como objetivos propagar a cultura da paz, estimular a troca de ideias e o intercâmbio entre as entidades dedicadas ao aperfeiçoamento, à divulgação e à prática da mediação de conflitos, além de posicionar-se com relação às propostas legislativas de forma a contribuir para a produção normativa em Mediação.

Considerando o surgimento dessas entidades em concomitância com a juridicidade apresentada - começando pelos atores presentes nos mutirões pela conciliação, as Casas de Justiça e Cidadania e seus formatos itinerantes juntamente com as entidades e organizações sociais emergentes, inclusive com a presença da participação popular -, vão sendo forjados os principais passos para a formação e a consolidação de uma rede associativa. Tomando por base essas inovações, as práticas de Conciliação e Arbitragem definem e formam pari passu os critérios para a inclusão da Mediação como parte de um proces- 
so capaz de instituir no país uma nova mentalidade que valorize a prática e a cultura do consenso em alternativa à do litígio, abrindo caminho para outros meios de solução sem a obrigatoriedade de sentenças e laudos.

Essa dinâmica evidencia que as redes trazem novas significações, pois incorporam uma nova dimensão à formação da identidade do mediador à medida que o leva, segundo Muszkat (2005, contracapa) "a um potencial de resolução de problemas interpessoais, interorganizacionais e entre pessoas e organizações", o que o conduz a estar atento à especificidade e à multiplicidade em que está inserido.

\section{Códigos de ética e padrões de práticas}

No Brasil, o Código de Ética do Mediador está fundamentado em um conjunto de preceitos de conduta oriundos de organizações estrangeiras e nacionais, entre elas, a regulamentação do Estado Americano da Flórida (por ser um Estado-exemplo na mediação de conflitos); o Código de Mediação francês do CNM - Centro Nacional de Mediação; e os códigos de ética do CONIMA e CEMAPE (SALES, 2003). É norteado pela existência de normas éticas que visam fortalecer o reconhecimento social da Mediação e aponta para um campo profissional consonante com as premissas constitucionais de justiça e paz social.

O Código estabelece e acrescenta critérios próprios a serem cumpridos por mediadores que atuam em todo o território nacional, além daqueles que já podem estar submetidos em virtude dos conselhos de classe, ou ainda, de instituições ou entidades a que se encontram vinculados. Instaura como premissa básica a voluntariedade das partes, e pauta-se por um conjunto de princípios, valores e formas de atuação que orientam a conduta do mediador e a sua relação com o processo da mediação, os seus usuários, as instituições e a sociedade, estando entre os seus princípios, a imparcialidade, a credibilidade, a competência, a confidencialidade e a diligência.

O Código oferece também diretrizes para a prática e a formação do mediador, que requer conhecimento interdisciplinar e treinamento específico. Assim, tem como preocupação balizar a qualificação e o aperfeiçoamento técnico, contribuindo para a excelência da conduta e das habilidades profissionais do mediador. Classifica, enfim, que o Código de Ética é um instrumento que disciplina os princípios estruturantes do instituto da Mediação por meio de padrões de práticas que configuram uma dinamicidade que assenta a mediação para além de uma alternativa do judiciário, "transformando-a em um novo saber, numa transdisciplina que abandona os paradigmas científicos tradicionais, o reducionismo e o pragmatismo originais" (MUSZKAT, 2005, contracapa). 
Seminários, treinamento e desenvolvimento profissional do mediador

Segundo Sales (2003), a atenção dada à formação dos mediadores é tão recente quanto o reconhecimento do ofício. Entretanto, uma investigação atenta a dados desordenados desperta a atenção para um cenário relevante neste campo. Tribunais em vários estados, Centros, Institutos e Câmaras de Mediação vêm realizando uma gama de cursos de capacitação para mediadores. Há também um conjunto de publicações, seminários e congressos que contribuíram para impulsionar o desenvolvimento profissional do mediador.

O primeiro texto brasileiro publicado acerca do tema foi "O Direito de Família e a Mediação Familiar”, de Águida Arruda Barbosa, em 1997. No ano seguinte, é editado o primeiro livro brasileiro, intitulado "Mediação de Família", de autoria de Maria de Nazareth Serpa (CATÃO, 2009). Ainda em 1998, é realizado o I Congresso Brasileiro de Mediação e Arbitragem, em Curitiba/ PR, promovido pelo Instituto de Mediação e Arbitragem do Brasil - IMAB, inaugurando, assim, uma série de eventos técnico-científicos no campo da mediação, crescendo a cada ano até os dias de hoje.

Alguns centros de conciliação, mediação e arbitragem promovem cursos de formação e treinamento. Entre os mais relevantes estão os promovidos pelas Escolas de Administração Judiciária dos Tribunais de Justiça; o IMAB (vários estados); o MEDIARE/RJ, o CEMAPE/PE; o CBMA (vários estados); o INAMA - Instituto Nacional de Mediação e Arbitragem (SP); o CCRC - Centro Catarinense de Resolução de Conflitos e o IDH - Instituto de Desenvolvimento Humano (RS); e, mais recentemente, o CCMA - Câmara de Conciliação, Mediação e Arbitragem/RJ, todos procurando convergir em prol de temas pertinentes ao processo da mediação, à função do mediador e à simulação de casos.

Os Tribunais de Justiça de diversos estados oferecem cursos gratuitos, exigindo também, de forma voluntária, o cumprimento de uma carga horária da prática de observação, mediação, supervisão e participação em atividades afins com um número específico de horas. O IMAB conta com uma lista de profissionais treinados em vários estados e, para o cumprimento da formação, exige carga horária mínima teórica, prática de estágio, além da participação do aluno como observador e ouvinte.

Muitas universidades disponibilizam a disciplina de Mediação em cursos de graduação e pós-graduação, predominantemente na área do Direito. Algumas oferecem cursos de extensão e/ou realizam a mediação de conflitos em escritórios-modelo, como os casos da USP e PUC-SP, que firmaram convênio junto ao IMAB, e o da Universidade de Fortaleza, que assinou com a Defensoria Pública do Estado do Ceará. 
No campo da pós-graduação em Mediação há um conjunto de cursos presenciais e em EaD - Educação a Distância. Entre os presenciais lato sensu, destacam-se: a UCB - Universidade Católica de Brasília; a UCAM/AVM Faculdade Integrada (RJ); a Faculdade Batista de Minas Gerais; o IMED/RS; e a PUC-SP. No stricto sensu, a UNISC/RS contempla o tema na linha de pesquisa do Mestrado e Doutorado em Direito - Políticas Públicas no Tratamento do Conflito -, coordenado pela Prof ${ }^{a}$. Fabiana Marion Splenger. O mesmo ocorre na UFF/RJ, no Programa de Pós-Graduação em Sociologia e Direito, com a linha de pesquisa "Acesso à justiça e crítica das instituições político-jurídicas", que abre vagas para alunos que desejam pesquisar o campo da Mediação, sob a coordenação do Prof ${ }^{\circ}$. Fernando Gama de Miranda Netto.

Diversos sites também contribuem com cursos e/ou fazendo uma interlocução importante para a promoção do desenvolvimento profissional do mediador, entre outros, o SaberOnLine, o Mediarconflitos, o Mediativa, e o próprio Mediare, incentivando os estudos constantes na área.

\section{Qualificação e competência para a qualidade}

Advogados, psicólogos, assistentes sociais, educadores e agentes comunitários constituem a maioria dos profissionais que têm praticado a Mediação no Brasil. Fernandes (2005), ao compreender a mediação como um desafio lançado aos Assistentes Sociais na prática jurídica, conclui que a noção de acesso à Justiça precisa avançar e ser vista de modo mais amplo, e não apenas sob a forma de ingresso nos tribunais. Sintetiza a história do Serviço Social Judiciário para apresentar as novas possibilidades desse profissional para atuar como mediador, rompendo com correntes conservadoras e abrindo-se para atender novas demandas que respondam a princípios como a "liberdade de pensamento e a autonomia individual" (FERNANDES, 2005, p. 49), de forma a trazer para a linha de frente um profissional mais engajado com o movimento dos processos sociais.

A extensão das áreas de aplicação da Mediação não indica de forma alguma um profissional que seja pré-requisito para o ofício. Silva (apud CESARFERREIRA, 2009, p. 198) recomenda que mediadores advogados, quando no exercício da mediação, não atuem como advogados para que não haja incompatibilidade de funções, mas alerta para a "necessidade da presença de mediadores da área psicológica" de modo que haja um bom rapport e resultado em casos de conflitos familiares.

Seguindo essa linha, ao falar de competência para a mediação, outros defendem que: 
[...] o mediador (psicólogo ou de qualquer outra área habilitada) deverá, além de sua capacitação contínua e de sua habilidade clínica para mediar, reexaminar constantemente suas crenças, princípios e valores, e praticar de tal forma que o ajude a clarificar conscientemente que o essencial pode se abandonado, porém não deve deixar de ser investigado. Para a autora, os psicólogos capacitados a realizar essa "justiça restaurativa" devem honrar sua formação e garantir a aplicabilidade dos direitos e da cidadania do homem (SILVA apud ARSENIO, 2009, p. 200).

Essa questão da capacitação e formação do mediador oriundo da Psicologia há algum tempo vem sendo examinada. Na realidade, a possibilidade de constituir a mediação de conflitos enquanto objeto de estudo da Psicologia não chega a ser uma novidade. Em 2006, a convite do Ministério da Justiça, o CFP - Conselho Federal de Psicologia, por meio de suas regionais, e em parceria com a Associação Brasileira de Ensino de Psicologia e a Associação Brasileira de Psicologia Jurídica, reuniu-se com objetivo de pensar criticamente sobre os espaços de atuação dos psicólogos nos processos de mediação e conciliação, no Judiciário e fora dele. As propostas foram encaminhadas para o Encontro Nacional "Psicologia, Mediação e Conciliação", que ocorreu no mesmo ano.

O Relatório Final do Encontro expressa que o convite há muito tempo era esperado devido ao crescimento, desde a década de 1990, do número de psicólogos que se estendem ao campo da Mediação, bem como um número cada vez maior de técnicas aplicáveis. Considerando isso, e com objetivo de fomentar o emprego da mediação por psicólogos, o CFP conduziu o processo de construção de referenciais para qualificação destes profissionais e delineou aspectos norteadores para a organização do programa de formação, concebido como transdisciplinar.

No evento, a Comissão de Trabalho apoiada nas formações já existentes no campo da Mediação, concluiu que o profissional psicólogo deveria compor uma determinada caracterização para o seu aprimoramento. Sugeriu um conjunto de referências acerca de conteúdos a serem introduzidos ou incentivados nos cursos de graduação. Além disso, elencou alguns tópicos a serem ministrados no curso de capacitação. Como resultado, o Encontro culminou com uma série de encaminhamentos discutidos e aprovados para serem cumpridos e observados.

Contudo, não é simples verificar como essas deliberações foram recepcionadas em todo o território brasileiro. Somente uma investigação mais apurada junto aos Conselhos Regionais poderia oferecer esse detalhamento, o que não se apresenta como perspectiva neste trabalho. Pode-se, sim, constatar tenta- 
tivas na área quando o assunto trata-se de Qualificação e Competência. Uma delas é o curso de Aperfeiçoamento para mediadores oferecido pela COGEAE - Coordenadoria Geral de Especialização, Aperfeiçoamento e Extensão da PUC-SP, inicialmente promovido pelo Programa de Estudos Pós-Graduados em Psicologia Clínica, intitulado "Mediação: Intervenções Sistêmicas para a Resolução de Conflitos e Disputas em Diferentes Contextos".

Segundo a apresentação disponível no site do Programa em 2012, o objetivo do instituto era:

\begin{abstract}
Priorizar a produção do conhecimento referente à intervenção, prevenção e promoção de saúde de todo o tecido social, contemplando a diversidade de posicionamentos epistemológicos da Psicologia Clínica. (...) "O curso - em consonância com a evolução científica das últimas décadas -, vem sendo conduzido segundo uma perspectiva de colaboração interdisciplinar e a dialógica transdisciplinar (COGEAE, 2012).
\end{abstract}

Algum tempo depois, o curso estava inserido na linha de conhecimento da Saúde, indicado aos profissionais das áreas de Saúde, Justiça, Educação e Ciências Sociais, com o mesmo corpo docente, em sua grande maioria formado por psicólogos que atuam na área da família. Contudo, hoje não encontramos mais o curso disponível, ao menos com essa nomenclatura, mas é possível argumentar que a ciência psicológica a partir da sua ocupação em novos espaços da pesquisa e extensão no campo da Mediação, e da consolidação das referências construídas, pode dispor do seu conteúdo teórico-metodológico, possibilitando uma 'participação consensuada' na construção da formação do mediador, o que, por si só, implica em uma identidade solicitada a responder ao compromisso político de fornecer respostas ao enfrentamento das controvérsias que fazem parte da vida contemporânea.

\title{
O mediador em busca de uma identidade: uma contribuição da psicologia social e do multiculturalismo
}

Nos meios acadêmicos, mais do que nunca, têm-se sentido uma integração teórica na Psicologia envolvendo, principalmente, estudos interdisciplinares. Jodelet (2000) defendia uma posição de destaque para a Psicologia Social, argumentando que até então, no campo interdisciplinar, a Psicologia encontrava-se em segundo plano, estando menos atuante que as Ciências Sociais, o que hoje não tem razão de ser. Segundo a autora, a Psicologia Social, em particular, deveria definir sua contribuição para pensar as relações dos indivíduos e dos grupos em seus espaços de vida, compreendendo não somente que sentido 
é dado a esses espaços, mas, sobretudo, quais construções são operadas pelos sujeitos sociais.

Uma vertente crescente para essa integração é a que trata da relação entre a Psicologia Social e alguns estudos centrados na questão do homem contemporâneo. Entre eles, as análises no campo da referência identitária na globalização (ASSIS; CANEN, 2004; FELDMAN-BIANCO; CAPINHA, 2000; GIDDENS, 2002; LOPES, 2002; SAWAIA, 1999; SILVA, 2000; ZUGUEIB NETO, 2005); as análises psicossociais e ética dos processos dialéticos de inclusão-exclusão social (JODELET, 2001; SAWAIA, 2001; SAWAIA e NAMURA, 2001); a Psicologia no novo contexto mundial (NICOLACIDA-COSTA, 2003;); os riscos e as possibilidades de transitar e pesquisar nas fronteiras dos saberes (COSTA e BUJES, 2005); e, também, as reflexões pós-estruturalistas e pós-colonialistas que chegam com o campo dos estudos culturais (GUARECHI; BRUSCHI, 2003; SILVA, 2004; COSTA, 2000), multiplicando a interlocução da área da Psicologia Social com diferentes campos do conhecimento.

No campo sociopolítico, esse pressuposto do diálogo com outras disciplinas é apreciado também por alguns estudos (SANTOS, 2003a; 2003b; SCHERER-WARREN, 2000; TOURAINE, 1998), que apontam um direcionamento analítico para uma transformação promotora de justiça social, da democracia e da cidadania multicultural.

$\mathrm{Na}$ perspectiva de estudos dos processos identificatórios, trabalhos contemporâneos reforçam a dimensão das novas e variadas identidades flutuantes e movediças (EWALD, 2005; OLINTO, 2002) e um movimento de totalização destotalizada (MAHEIRE, 2005), que fazem cair por terra os ideais de estabilidade e segurança contidas nas marcações identitárias do passado.

Neste percurso, considerando que o trabalho ocupa lugar essencial na formação da identidade dos sujeitos, uma reflexão centrada no movimento de construção identitária do mediador, em uma perspectiva transformadora, pode articular uma reflexão sobre o saber e o saber-fazer do mediador de forma a ampliar o canal de comunicação entre os mediadores que buscam o seu aperfeiçoamento profissional perante as demandas inscritas no âmbito do acesso à justiça.

A identidade tem sido tema recorrente na Psicologia Social, notadamente quando se trata das relações identidade e trabalho. Moraes (2009), ao fazer um relato sobre as produções científicas brasileiras, é contundente no que concerne a analisar a relação da atividade com o desenvolvimento da identidade, principalmente, quando associada à subjetividade. 
As explicações e definições deste tema associam-se à transformação / permanência, exclusão / inclusão, indivíduo / sociedade, igual / diferente, entre outros binômios que têm a função de expressar o desenvolvimento da identidade com sentido de movimento, transformação, fluidez e metamorfose (MORAES, 2009, p. 1).

Sawaia (2001) aponta para as ambiguidades que tratam o tema, levando em conta os processos de inclusão/exclusão e suas determinações na vida contemporânea, alertando para a necessidade de ponderação frente às motivações que direcionam o resgate do tema das identidades como estratégia de relacionamento em defesa do direito à diferença, quer no cotidiano, quer no plano social-coletivo. Para a autora, se de um lado atribui-se à identidade a tarefa de resguardar a multiplicidade das individualidades para considerar a alteridade, de outro, recorre-se a esta referência para enfrentar no plano social ou individual a indeterminação, a multiplicidade e o receio ao diferente.

Esse subtexto paradoxal reforça, para Sawaia (2001, p. 123), a tese de que identidade é "uma categoria política disciplinadora das relações entre pessoas, grupo ou sociedade, usada para transformar o outro em estranho, igual, inimigo ou exótico", o que legitima comportamentos excludentes de toda ordem. Neste contexto, pesquisar identidade e utilizar a referência identitária num mundo onde as contradições e diversidades estão exigindo novas respostas, pode adquirir o sentido de desvelar a multiplicidade das individualidades.

A Mediação, pela qualidade de sua produção e caráter interdisciplinar, vem se consolidando de forma comprometida com o espaço sociopolítico quando se trata de acesso à justiça e políticas públicas. Uma contribuição importante a apresentar ao tema da formação identitária do mediador vem do Multiculturalismo. Nas quase três últimas décadas, o Multiculturalismo tem sido marcante em diferentes âmbitos de debate e tem tido expressão ímpar nas discussões acerca do tema da identidade. Trata-se de um campo de estudos bastante dinâmico que apresenta uma expressiva produção em termos teóricometodológicos (HALL, 2003; McLAREN, 2000; BHABHA, 2005; TAYLOR, 1998; GONÇALVES; SILVA, 2001; SILVA, 1999; CANEN, 2007), oferecendo novas perspectivas e critérios a explorar no que tange à questão do consenso. Urt (2004) discutindo a contribuição da Psicologia para o Multiculturalismo, enfatiza que:

A Psicologia pode contribuir para a compreensão das questões do multiculturalismo desde que considere a diferença como algo produzido pela natureza histórica do homem e não como 
algo dado, natural”(...). “O papel da Psicologia na questão das diferenças deve ser o de apontar essas diferenças e, principalmente, desvelar suas causas, identificando as condições concretas de vida e a maneira como ocorre o processo de desenvolvimento e de apropriação do saber (URT, 2004, p. 4).

Essas ideias que valorizam os múltiplos discursos e rejeitam as posturas que naturalizam as identidades aparecem também no trabalho de Canen (2007). A autora destaca três premissas sobre a construção da identidade sob a perspectiva do olhar do multiculturalismo crítico que tem por base a política cultural da diferença: identidade concebida em contínua construção, provisória, constituída e reconstituída nas relações sociais; identidade como processo de construção que envolve 'marcadores' plurais, tais como raça, etnia, classes sociais, cultura e outros; e, por último, a sociedade sendo formada na pluralidade de identidades, o que envolve as relações de poder que constituem as formas discursivas oficiais.

Frente à emergência do indivíduo moderno, e objetivando criar condições para um multiculturalismo emancipatório - termo compreendido por Souza Santos (2005) como um projeto político e cultural - e não apenas como um conjunto de definições -, há um importante aspecto nesta implicação: a produção das subjetividades. Compreendendo-a, ao contrário de sua perspectiva utilitarista e transformada em força produtiva, mas que revele questões em torno da reificação das identidades coletivas, das cidadanias plurais, das disputas pelo reconhecimento e a como os diferentes tipos de luta sofrem um desajustado enquadramento nos processos transnacionais.

A partir de tais considerações, podemos afirmar que essas formas discursivas oficiais convidam para a necessidade de repensar o trabalho da mediação, uma vez que se apresenta como um caminho para aprofundar o entendimento das formas de acesso à justiça, o papel dos mediadores e a sua formação. Conforme Canen (2007), o vínculo está no relacionamento humano, direcionando-nos para perceber as relações de poder que estão em jogo, haja vista que há um constituir-se constante que movimenta o princípio ético da não-cristalização.

Compreendendo e avançando com Sawaia e Canen, é legítimo olhar a referência 'identidade' como um processo constante de configuração de significações, o que pode traduzir a criação de uma nova estética ao questionar a construção discursiva das diferenças e das identidades. Nesta perspectiva, significa não se contentar com a legitimidade dada aos discursos oficiais, conforme salienta Canen (2005), tampouco com as ações particulares e alterações de ordem privada, tão em voga hoje, como se aí estivessem o local da trans- 
formação da ordem pública. Refletir sobre a transformação social significa também reinventar linguagens que reinventem novas narrativas e, estas, novos engendramentos, diversos e complexos.

É preciso considerar que, ao nos perguntarmos sobre a formação do mediador, estamos investigando desafios. Não apenas em torno da sua capacidade de responder aos anseios de realizar na prática o ideal de igualdade e respeito à diferença, consagrado em nossa constituição, mas, por que não dizer, sobre o trabalho comprometido com a transformação, quer social, quer da própria subjetividade. Daí o seu vínculo com um campo de interconexões de indivíduos e instituições, em que os acontecimentos e processos são compartilhados com os sujeitos envolvidos na ação.

Problematizar essas reflexões estimula o debate que encobre os diferentes jogos discursivos para o qual cada profissional pode contribuir, principalmente, no que concerne ao campo da diferença cultural, e não o da diversidade cultural. Assim prefere Bhabba (2005), quando interroga sobre a identidade e manifesta-se em favor desse ser um caminho inovador e politicamente crucial, pois supera a necessidade de concentrar-se nas narrativas de "subjetividades originárias e iniciais", podendo convergir para momentos ou processos produzidos na articulação das diferenças culturais. Para Bhabba (2005), é possível não se deter somente nas singularidades de categorias como classe e gênero, mas dirigir-se para um terreno onde são elaboradas e negociadas outras estratégias de subjetivação singulares e coletivas; portanto, formadoras de novos signos de identidade e de novas maneiras de colaboração e contestação que definem a própria ideia de sociedade.

Por sua vez, Bauman (2005), alerta para a responsabilidade do pesquisador frente às pesquisas e estudos identitários, deixando claro que 'pertencimento' e 'identidade' não são garantias de solidez. Ao contrário, são tarefas a realizar, pois a identidade deve ser inventada, ser um alvo a perseguir, uma constante construção, jamais descoberta, por isso, ser refletida à luz da transitoriedade.

\section{É possível conjugar consensos?}

Vimos que diferentes estudos, com objetivos distintos, analisam a questão da identidade. Entretanto, trabalhar com a referência identitária envolve um terreno movediço, pois não é um campo linear.

Identidade esconde negociações de sentido, choques de interesse, processos de diferenciação e hierarquização de diferenças, configurando-se como estratégia útil de regulação das relações 
de poder, quer como resistência à dominação, quer como seu reforço, portanto, "não basta perguntar pela identidade, é preciso conhecer quem pergunta, com quais intenções e sentimentos se pergunta (SAWAIA, 2001, p. 123).

Esse alerta significa compor riscos de partir da confluência entre a Mediação, Psicologia Social e o Multiculturalismo com fins de articular o fenômeno identitário. A perspectiva dos Estudos Culturais e Multiculturais aponta para uma noção de sujeito que passa a ser refletido através da cultura. Alguns autores nos fazem compreender que as identidades sociais são:

[...] resultado de um processo de identificação que permite que nos posicionemos no interior das definições que os discursos culturais (exteriores) fornecem ou que nos subjetivemos (dentro deles). Nossas chamadas subjetividades são, então, produzidas parcialmente de modo discursivo e dialógico (GUARESCHI, MEDEIROS; BRUSCHI, 2003, p. 45).

O multiculturalismo crítico (MC LAREN, 2000), com sua agenda política transformadora, compreende as representações de raça, etnia, classe, gênero, culturas, religiões etc., no relacionamento intercultural, como resultado de embates maiores. Apoia-se no conceito de hibridização identitária, dado que as identidades se cruzam em direção à formação de novas identidades, na pluralidade de marcadores identitários, em um movimento constante de aceite das 'diferenças dentro das diferenças' e na compreensão de que as identidades não são puras.

Pode-se dizer, com isso, que existem potenciais de reconhecimento para se construir novas diversidades; para desvelar em que medida as hibridizações são ou não valorizadas nas práticas sociais, além de elucidar em que teias de significados se configuram as identidades no âmbito de um espaçotempo específico.

Partir do argumento de que romper limites profissionais significa transitar por fronteiras, e pensar a construção identitária de um importante segmento, como o ofício do mediador, pode provocar sinergias capazes de produzir interferências positivas. No caso dos métodos autocompositivos de solução de conflitos, cada vez mais a Mediação se destaca, haja vista que pretende efetivar uma Cultura de Paz e de Educação para a resolução do conflito. Nestes termos, ao surgir como um instrumento de transformação cultural e de qualificação participativa nos diversos assuntos de interesse de um grupo, suprime os tradicionais sistemas de imposição e uso abusivo de poder por meio de relações dialógicas, pautadas por acordos e alianças, seja no Judiciário ou não. 
Essa perspectiva de atuação apresenta-se como terreno fértil à medida que circula saberes e avança fronteiras no que tange ao campo do conhecimento no tratamento privado da resolução de conflitos. O próprio Código de Ética do mediador disciplina os princípios estruturantes do instituto da Mediação por meio de padrões de práticas que configuram uma dinamicidade que estabelece a mediação para além de uma alternativa do Judiciário, conforma salienta Muskat (2005, contracapa), "transformando-a em um novo saber, numa transdisciplina que abandona os paradigmas científicos tradicionais, o reducionismo e ao pragmatismo originais".

Conjectura-se, a partir disso, um quadro que permite visualizar o mediador transformando-se no tempo e espaço, construindo e fortalecendo métodos de resoluções de conflitos, uma vez que acompanha o movimento de mudança social nos mais diferentes âmbitos de atuação - mediação familiar, comunitária, escolar, cível, empresarial, ambiental, entre outros.

Ademais, o ofício consolidou-se no Brasil através da consistência de uma rede de relações significativas, inclusive com a presença da participação popular. Tais constatações evidenciam que essas redes trazem novas significações, pois incorpora outra dimensão à formação da identidade do mediador enquanto que o apresenta, segundo Muszkat (2005, contracapa) "a um potencial de resolução de problemas interpessoais, interorganizacionais e entre pessoas e organizações", o que nos conduz a estar atento à especificidade e à multiplicidade em que esse profissional está inserido.

Conceitualmente, as redes sociais são articulações e interações entre organizações e grupos que têm como objetivo criar, ampliar e consolidar a cidadania ativa, expandindo a solidariedade e apontando para as relações de cooperação, deixando surgir os atores sociais. Essa compreensão histórica e social das redes sociais implica também identificar a Mediação como um instrumento de acesso à justiça e de pacificação social.

Se entendermos a mediação como uma das práticas alternativas de disputa, portanto, fundada no reconhecimento da política pacífica entre atores e redes, a cada fala o homem reinterpreta o que está sendo dito, compondo, assim, o caráter da alteridade que todo discurso possui. Esse terceiro - mediador - é o facilitador, o tradutor dessa estrutura complexa profundamente enraizada nas ligações entre a história individual e a história social.

A experiência de contar e recontar histórias, comumente narradas na mediação, mostra que o saber produzido circula e coloca em jogo a construção da subjetividade gradativamente, facilitando a re-singularização. A experiência de narrar histórias mostra que o saber produzido circula e é ressignificado. 
Todo ato de fala em que o falante se entende com outra pessoa sobre algo, situa a expressão linguística em relação ao falante, ao ouvinte e ao mundo. Assim, acontece uma ação comunicativa a partir de atos ilocucionários de fala, na qual um dos aspectos é a relação interpessoal cujo interesse é especialmente importante quando se pretende discutir outras formas de tratamento dos conflitos (como a mediação) enquanto meio de obter consenso (SPLENGER, 2010, p. 361).

A partir de tais considerações, é possível inferir que resgatar a vida a partir das práticas cotidianas e trabalhar com a enunciação significa instaurar outra narratividade, ou melhor, uma nova alteridade na narrativa. No exercício da mediação, não importa a formação do facilitador terceiro - advogado, psicólogo, assistente social, educador e agente comunitário, entre outros -, mas sim, entendê-los como sujeitos portadores de cultura, e por onde a articulação e a originalidade do trabalho dão-se através da narrativa. Conforme enfatizou Carlos Fuentes, respeitado poeta latino-americano, a história não terminou porque não terminamos de contar histórias: "enquanto houver vida, haverá narrativa. Haverá narravida” (ZAPPA; GUEDES, 1999, p. 1-B).

\section{Considerações finais}

O presente artigo identificou alguns estudos de identidade com objetivo de refletir sobre a formação identitária do mediador de conflitos. Neste itinerário, percebeu-se a complexidade em definir uma identidade que emitisse de forma uníssona o ofício do mediador, uma vez que sua prática perpassa diversos aspectos que ocorrem na cultura, que, por sua vez, circula e manifesta uma dimensão intersubjetiva que se quer aglutinadora para ser inclusiva.

Explorando historicamente a formação e o aprimoramento do mediador na sociedade brasileira, identifica-se um conjunto de trajetos oriundos de diferentes projetos que se consolidam na prática social. Trajetos constituídos basicamente por espaços de discussão e problematização da realidade, que ocorrem mais propriamente no entrelaçamento das tarefas no campo da construção da cidadania.

À medida que o conhecimento aponta para os debates e as lutas por afirmação e reconhecimento às múltiplas etnias, culturas, linguagens, civilizações, religiões e outros determinantes, pode-se afirmar que é possível conjugar consensos com estudos que articulem teoria e práticas multiculturais, buscando contribuir para formas de tradução sobre o saber e o saber-fazer do mediador de conflitos. 
Assim, o presente artigo atingiu o seu propósito no que concerne à reafirmação da perspectiva que nos distancia das concepções naturalizantes do fenômeno psicológico e que nos aproxima de saídas que valorizam as construções históricas e a visão transformadora do homem sobre o mundo.

Não se pretendeu esgotar a temática, mas destacar que o ofício do mediador passa transversalmente pela combinação das identidades individuais, coletivas e institucionais que contribuem e estão presentes, cada qual com sua espacialidade/totalidade, metamorfoseando-se a partir dessa relação.

\section{Referências}

BACELLAR, Roberto P. O Poder Judiciário e o Paradigma da Guerra na Solução de Conflitos. In: RICHA, Morgana de Almeida; PELUSO, Antônio Cezar (Orgs.). Conciliação e Mediação: Estruturação da Política Judiciária Nacional. Rio de Janeiro: Ed. Forense, 2011, p. 31-37.

BAUMAN, Zygmunt. Identidade. Rio de Janeiro: Jorge Zahar Editores, 2005. 110p.

BHABHA, Homi K. O Local da Cultura. Belo Horizonte: Ed. UFMG, 2005. 386p.

BRANCHER, Leoberto N. Justiça Restaurativa: A cultura de Paz na Prática da Justiça. Disponível em: http://jij.tj.rs.gov.br/jij site/docs/just restaur/vis $\% \mathrm{C} 30+$ geral + jr $0 . h t m$ Acesso em: 09 jun. 2011.

BRASIL (Ministério da Educação, Conselho Nacional de Educação). Resolução CNE/CP n. ${ }^{\circ}$ 1, de 30 de maio de 2012. Estabelece Diretrizes Nacionais para a Educação em Direitos Humanos. Diário Oficial da União. Brasília, DF, 30 mai. 2012, Seção 1, p.48. Disponível em: http://portal.mec.gov.br/index.php?option=com content\&id=17810\&Itemid=866 Acesso em: 18 mai. 2014.

CANEN, Ana. O multiculturalismo e seus dilemas: implicações na educação. Comunicação \& Política, Rio de Janeiro, v.25, p.91-107, 2007.

CANEN, Ana; ARBACHE, Ana Paula; FRANCO, Monique. Pesquisando Multiculturalismo e Educação : o que dizem as dissertações e teses. Educação e Realidade, Porto Alegre, v. 26, n.1, p. 161-181, 2001.

CARMONA, Carlos A. A Arbitragem como Meio Adequado de Resolução de Litígios. In: RICHA, Morgana de Almeida; PELUSO, Antônio Cezar (Orgs.). Conciliação e Mediação: Estruturação da Política Judiciária Nacional, Rio de Janeiro: Ed. Forense, 2011, p.199-210.

CATÃO, Ana L. C. Mediação e o Judiciário: Problematizando fronteiras psi-jurídicas. 2009, 179 f. Dissertação (Mestrado em Psicologia Social). Pontíficia Universidade Católica de São Paulo, São Paulo, 2009.

COGEAE (Coordenadoria Geral de Especialização, Aperfeiçoamento e Extensão da PUC-SP. Apresentação do curso: "Mediação: Intervenções Sistêmicas para a Resolução de Conflitos e Disputas em Diferentes Contextos”. Disponível em: http://cogeae.pucsp.br/cogeae/curso/85 Acesso em: 26 abr. 2012. 
CONSELHO FEDERAL DE PSICOLOGIA. Consolidação das referências construídas pelos representantes regionais no Encontro. In: I Encontro Nacional de Psicologia e Mediação .Relatório Final, Brasília, DF: 7 e 8 dez. 2006. p. 37- 42.

DEMO, Pedro. Participação e Avaliação - projetos de intervenção e ação. In: SPOZATI, A. et al. Ambientalismo e participação na contemporaneidade. São Paulo: Educ/Fapesp, 2002. p.166-184.

EWALD, Ariane P. Identidade e construção do sujeito numa era de incerteza. In: ZUGUEIB NETO, J. (Org.). Identidades e crises sociais na contemporaneidade. Curitiba: Ed. UFPR, 2005, p. 215-231.

FERNANDES, Vanessa. Mediação: um desafio ao serviço social. 2005, 81 f. Trabalho de Conclusão de Curso (Bacharelado em Serviço Social). Universidade Federal de Santa Catarina, Florianópolis, 2005.

GUARESCHI, Neusa Ma de Fátima; BRUSCHI, Michel E. (Orgs.). Psicologia Social nos Estudos Culturais: perspectivas e desafios para uma nova psicologia social. Petrópolis, RJ: Ed. Vozes, 2003, p. 23-49.

GUIMARÃES, Marcelo Rezende. O futuro não será caos e miséria: fortalecendo uma cultura de paz. Cadernos da ESTEF (Escola superior de Teologia e Espiritualidade Franciscana). Por uma cultura da paz, nº. 29, Porto Alegre, p. 5-23, 2002.

HOUAISS, A. Dicionário eletrônico Houaiss da língua portuguesa. São Paulo: Objetiva, 2002.

JODELET, Denise. Os processos psicossociais da exclusão. In: SAWAIA, B. As Artimanhas da Exclusão. Petrópolis: EDUC, 2001, p.53-66.

MAHEIRIE, Kátia. A singularidade do sujeito e o engajamento do coletivo. In: ZUGUEIB NETO, J. (Org.). Identidades e Crises Sociais na contemporaneidade. Curitiba: Ed. UFPR, 2005, p. 233-243.

McLAREN, Peter. Multiculturalismo Crítico. São Paulo: Cortez, 2000. 240 p.

MOORE, Christopher W. O Processo de Mediação: estratégias práticas para a resolução de conflitos. Porto Alegre: Ed. Artmed, 1998. 368p.

MORAES, Ana B. T. Identidade e trabalho: um relato sobre as produções científicas brasileiras. In: ENCONTRO NACIONAL DA ASSOCIAÇÃO BRASILEIRA DE PSICOLOGIA SOCIAL, ABRAPSO, 15, 2009, Maceió, AL. Anais...Maceió, FIT, 2009, Disponível em: http:// www.abrapso.org.br/siteprincipal/images/Anais_XVENABRAPSO/365.\%20identidade $\% 20$ e\%20trabalho.pdf Acesso em: 20 jun. 2013.

MUSZKAT, Malvina E. Guia Prático de Mediação de Conflitos em famílias e organizações. São Paulo: Ed. Summus, 2005. 101p.

OLINTO, H.K. Carteiras de Identidade(s) de validade limitada. In: LOPES, L. P. da M.; BASTOS, Liliana Cabral. (Orgs). Identidades - recortes multi e interdisciplinares. Campinas, SP: Mercado de Letras, 2002, p. 257-266. 
OLTRAMARI, Leandro C. Mediação Familiar nos contextos de conjugalidade. In: ROVINSKI, S.L.R; CRUZ, Roberto M. Psicologia Jurídica: perspectivas teóricas e processos de intervenção. São Paulo: Ed. Vetor, 2009. 315 p.

PINENT, Carlos E. da C. Sobre os mundos de Habermas e sua ação comunicativa. Porto Alegre: Revista da ADDPUCRS, Porto Alegre, nº 5, p.49-56, dez. 2004.

PINTO, José Marcelo R. A teoria da ação comunicativa de Jürgen Habermas: conceitos básicos e possibilidades de aplicação à administração escolar. Revista Paidéia, Ribeirão Preto, v. 5, n. 8/9, p. 77-96, 1995.

ROZEMBERG, Marshall B. Comunicação Não-Violenta: técnicas para aprimorar relacionamentos pessoais e profissionais. São Paulo: Ágora, 2006. 285p.

SALES, Lídia M. de M.S. Justiça e Mediação de Conflitos. Belo Horizonte: Ed. Del Rey, 2003. 334p.

SANTOS JR., Belizário. Apresentação. In: MUSZKAT, Malvina. E. Mediação de conflitos: pacificando e prevenindo a violência. São Paulo: Summus Editorial, 2003, p.7-9.

SANTOS, Boaventura de Sousa. Dilemas do Nosso Tempo: globalização, multiculturalismo e conhecimento (entrevista). Currículo sem Fronteiras, [S.1.], v.3, n. 2, p.5-23, jul./dez 2003 a.

Reconhecer para libertar: os caminhos do cosmopolitismo multicultural. RJ: Civilização Brasileira, 2003b.

SOARES, Luiz E. Segurança Pública: presente e futuro. Estudos Avançados, São Paulo, v.20, n.56, jan./abr. 2006.

SAWAIA, Bader Burihan. Identidade - uma ideologia separatista. In: SAWAIA, Bader B. As Artimanhas da Exclusão. Petrópolis: EDUC, 2001, p.119-127.

.O sofrimento ético-político como categoria de análise da dialética exclusão-inclusão. In: SAWAIA, Bader B. As Artimanhas da Exclusão. Petrópolis: EDUC, 1995b, p. 97-118.

SILVA, Denise Maria P. Psicologia Jurídica no Processo Civil Brasileiro: a interface da psicologia com o direito nas questões de família e infância. Rio de Janeiro: Ed. Forense, 2009. 464 p.

SPLENGER, Fabiana M. Da Jurisdição à Mediação: por uma outra cultura no tratamento de conflitos. RS: Ijuí: Ed. Ijuí, 2010. 427p.

SPLENGER, Fabiana M.; SPLENGER NETO, Theobaldo Mediação: um retrospecto histórico, conceitual e teórico. In: SPLENGER, Fabiana M.; SPLENGER NETO, Theobaldo (Orgs.). Mediação enquanto política pública: a teoria, a prática e o projeto de lei. Santa Cruz do Sul: EDUNISC, 2010b, p. 17-57.

WARAT, Luiz A. Educação, Direitos Humanos, Cidadania e Exclusão Social: Fundamentos preliminares para uma tentativa de refundação. Disponível em http://portal.mec.gov.br/sesu/ arquivos/pdf/educacaodireitoshumanos.pdf Acessado em: 02 mai. 2011.

. Direitos Humanos: Subjetividade e Práticas Pedagógicas. In: SOUZA JR. et al. (Orgs.). Educando para os Direitos Humanos: pautas pedagógicas para a cidadania na Universidade. Porto Alegre: Síntese, 2004. 

$423 \mathrm{p}$. Surfando na pororoca: o oficio do mediador. Florianópolis: Fundação Boiteux, 2004,

URT, Sonia da C. Multiculturalismo: uma interface da educação e psicologia. In: ENCONTRO DE HISTÓRIA DE MATO GROSSO DO SUL. 7. - Patrimônio Histórico e Cultural: Identidade e Poder, 2004, Campo Grande. Anais... Campo Grande, UCDB, 2004. v. 1. p. 1-9.

ZAPPA, Regina; GUEDES, C. Pela cultura da tolerância. Jornal do Brasil, Caderno B, p.1-B, Rio de Janeiro, 29 jun. 1999.

Submissão em: 10/02/2015

Revisão em: 28/03/2015

Aceite em: 04/04/2015

Aurila Eurídice Carneiro da Cunha Souza é psicóloga e Mestre em Psicologia Social. Pós-graduada em Mediação de Conflitos (AVM/UCAM-RJ); em Teoria e Práxis do Meio Ambiente (ISER/RJ); e em Psicologia para o Magistério Superior (UNIVALI/SC). Mediadora Voluntária do Centro de Mediação do Fórum Central e da Comarca de Duque de Caxias do Tribunal de Justiça/RJ e Consultora em Mediação de Conflitos e Facilitação de Diálogos. Endereço para correspondência: Rua Santo Eulógio, 77. Freguesia, Rio de Janeiro/RJ. CEP 22743-610. E-mail: lilacunha@terra.com.br 